\title{
El diseño gráfico en México. Un análisis histórico
}

\author{
Oscar Salinas Flores
}

Historia, Cultura,

Identidad, desarrollo,

Este artículo analiza el origen, desarrollo y transformación de la profesión del diseño gráfico en México. Asimismo muestra la importancia de la relación entre la cultura que ha dado sentido a la evolución de sus sociedades a través del tiempo y las diversas expresiones del diseño, que ha podido integrar a las influencias que históricamente han arribado al país y generado el sincretismo que caracteriza al diseño mexicano.

¿Dónde empieza el camino de una profesión como el Diseño Gráfico? Si lo queremos ver como una disciplina profesional, apenas tiene poco mas de medio siglo en México; no obstante, este estudio analiza el pasado para encontrar los antecedentes que dieron paso al origen de un oficio que en sus inicios se encontraba ligado al término de "artista"; una expresión que iba mas allá de la capacidad técnica de resolver los problemas de la impresión de libros y otros productos que comunicaban a la sociedad el conocimiento y el acontecer del momento. Mas tarde, esto dio origen a una profesión que nació ante la necesidad de una sociedad que requería de un especialista que aportara las soluciones necesarias para una sociedad en crecimiento continuo, impulsando el inicio de una disciplina universitaria. Ésta se encargaría de formar a los profesionales responsables a través del diseño para la comunicación gráfica, diseño para la comunicación visual o los nuevos conceptos que la identifican como un gremio preparado para responder a través de esa formación al contexto de sistemas y sociedades cada vez mas complejas que conforman al mundo que hoy nos toca vivir.

En México, las bases de ese oficio las encontramos en las llamadas

1 Área geográfica que según el antropólogo alemán Paul Kirchhoff concentra a las altas culturas, hacia el momento de la conquista, ubicada entre el norte de lo que hoy es México y Honduras, y abarca mas de 2500 años de antigüedad. altas culturas de Mesoamérica,1 donde existían especialistas que para comunicarse utilizaron ideogramas, signos y representaciones gráficas que muestran una gran capacidad expresiva. De diversas maneras tenían como fin último el comunicar todo aquello que atañía a su comunidad pero también los hechos mas importantes de su cultura, su relación con el cosmos y el soporte a sus mitos y a su devenir histórico. De este modo los mayas, mixtecos o aztecas legaron sus conocimientos al futuro, al plasmarlos en recipientes, estructuras arquitectónicas o en documentos conocidos como códices utilizando distintos medios de impresión.

En el caso de la arquitectura, desarrollaron pinturas murales integradas a construcciones religiosas y domésticas, cargadas de un profundo simbolismo. Casos como el de las ciudades de Bonampak y 
Cacaxtla dejan constancia de la gran maestría de sus creadores, que además de la perfección en el dibujo, incorporan un colorido notable, utilizando colorantes y tintes, como es el caso del llamado azul maya, color extraído de la hierba de añil, que por mezclarse naturalmente con ciertas arcillas del suelo mexicano, da como resultado un bellísimo azul esmeralda altamente duradero y resistente a diversas sustancias que usualmente deterioran a los colores, y una tonalidad que no se da en ningún otro lugar del mundo. (Salinas Flores, 2010).

Figura 1 Códice Zouche-Nuttall, Hoja 80. Reproducción facsimilar, colección OSF

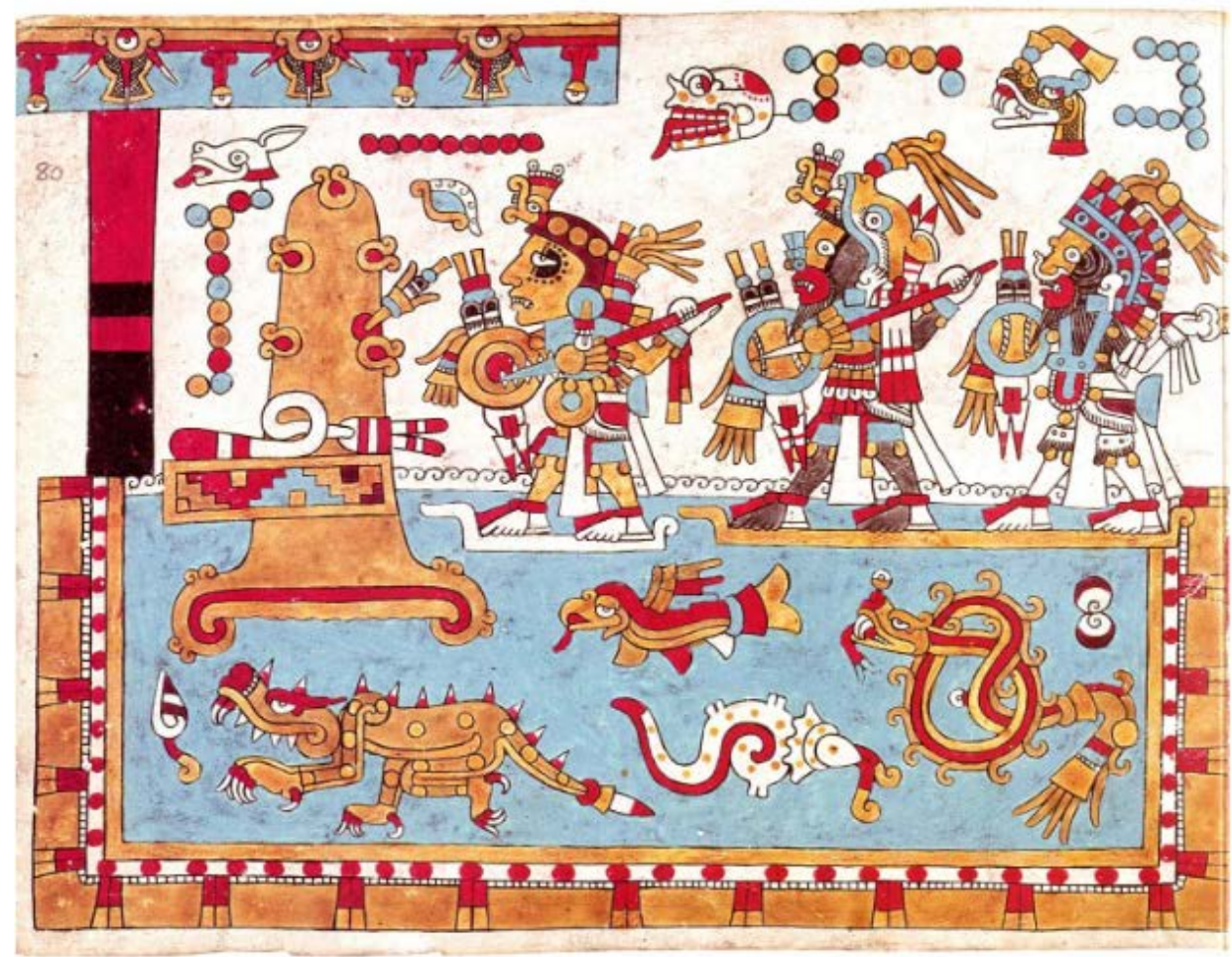

Estas culturas, lograron estructurar un complejo código de comunicación visual que les permitió preservar el conocimiento y las experiencias vividas en conjunción con la naturaleza, a través de los amoxtli o libros hoy llamados códices prehispánicos. Nos muestran diversos registros históricos a través de signos glíficos, representaciones de objetos, ideas y aún fonemas usualmente portadores de múltiples formas de significación.

\section{Colonización y Virreinato}

Al consumarse la conquista de los españoles en 1521, se inicia el período de la colonización, la nueva cultura se caracteriza por un marcado sincretismo en muchas de las expresiones populares, y por ello, lo mismo encontramos dos religiones superpuestas, que un arte 
2 Procedimiento de impresión inventado por el alemán Aloys Senefelder en 1796. barroco indiano o un nuevo tipo de convento que debe mucho al concepto urbano de las sociedades prehispánicas.

No obstante, la gráfica indígena es casi borrada en el contexto virreinal. Recordemos cómo la destrucción de códices sólo nos ha permitido conocer hoy en día poco mas de una decena de estos magníficos testimonios pictográficos, que además se encuentran en su mayoría en manos de instituciones europeas.

Dentro de la nueva sociedad colonial, las lenguas indígenas se marginan y la comunicación gráfica tiende a ser un reflejo de los cánones europeos. Los primeros textos impresos en la Nueva España hoy México- a partir de 1539 bajo la mano de Juan Pablos, acompañado por el tipógrafo Antonio de Espinosa y Pedro Ocharte, son el inicio de casi tres siglos de una obra gráfica que avanza lentamente, sin definir un estilo propio y original frente a otras naciones.

Es hasta fines del siglo XVIII, que llega la litografía a México, ${ }^{2}$ y ofrece a los artistas un medio mas económico que facilita la comunicación con un público masivo. Este procedimiento de impresión en piedra nace y se desarrolla asociada con el periodismo, lo transforma con sus ilustraciones y es el origen del periodismo gráfico, expresión moderna aún vigente. El primer periódico ilustrado con litografías es El Iris (1826) ejecutado por Claudio Linati, y le sigue en 1845 El Gallo Pitagórico ya ilustrado por litógrafos mexicanos como Joaquín Heredia, Placido Blanco y Hesiquio Iriarte e impreso en el taller de Ignacio Cumplido. El periódico político La Orquesta, probablemente el mas importante de su tiempo, fue ilustrado con mas de 1000 litografías entre 1861 y 1877.

Figura 2 El presupuesto / publicado en El Ahuizote (1874), Litografía a lápiz. José María Villasana, Colección OSF

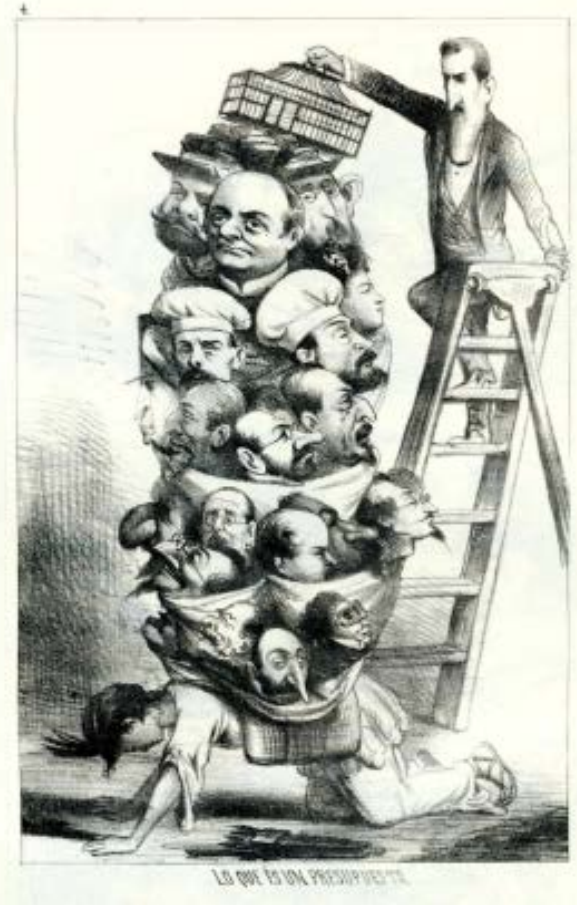


3 Ahuizote, en lengua nahuatl, es "perro de aguas" animal mítico que tenia manos al final de las patas y la cola, con las que capturaba a la gente, después de seducirlos para que se acercaran a él en el agua.
Los litógrafos del siglo XIX, fueron cronistas de su tiempo, pero también líderes culturales y en algunos casos, líderes políticos que introdujeron nuevos valores estéticos y generaron distintos patrones de vida y de conducta. Se puede decir que el periódico de oposición a la dictadura del general Porfirio Díaz, El Hijo del Ahuizote (1885-1903) movió a las multitudes hacia lo que sería la Revolución Mexicana. ${ }^{3}$

Junto a ellos, destacaron los llamados litógrafos viajeros, que llegaron al México independiente a partir de 1825 como parte de expediciones científicas con el noble propósito, decían ellos, de dar a conocer en Estados Unidos y Europa la naturaleza y las costumbres de ese nuevo país. Aunque también, de manera disfrazada, registrar y cuantificar los recursos naturales y conocer las condiciones políticas y económicas del país, con la posibilidad, siempre presente, de colonizar nuevamente y explotar los recursos naturales a su conveniencia. Los pintores y litógrafos Carl Nebel, Daniel Thomas Egerton, Frederick Catherwood, John Phillips y Pietro Gualdi entre otros, descubrieron, nuestros paisajes arqueológicos, urbanos y campestres y supieron plasmar con acierto nuestros tipos sociales, nuestras costumbres e indumentaria a través de álbumes de series litográficas, muy de moda entonces. (Pérez Escamilla, 1994)

La técnica de la litografía se utilizó durante prácticamente todo el siglo XIX e inició su decadencia con la aparición de las nuevas técnicas de reproducción de imágenes de finales de ese siglo como el offset y el fotograbado.

Figura 3 Valle de México / detalle, (1837), Óleo sobre tela, Daniel Thomas Egerton, Archivo MuNal

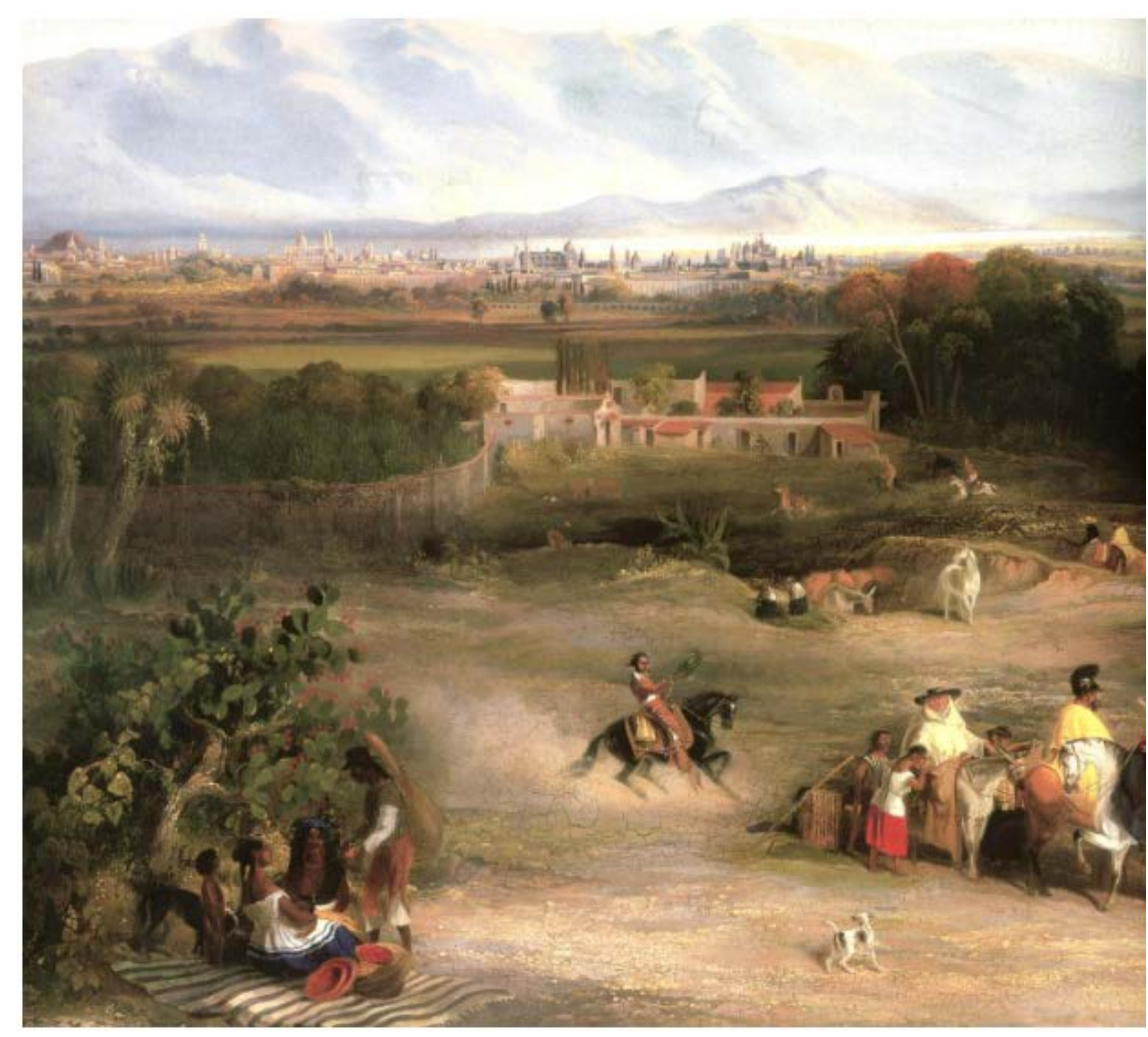




\section{La identidad posrevolucionaria}

Durante el periodo final del largo gobierno de Porfirio Díaz (18761910) destaca la gráfica de carácter político de José Guadalupe Posada que iba desde las hojas sueltas o "volantes" con noticias sensacionalistas acompañadas por grabados descriptivos y de escándalo, tal como ya se había utilizado en algunos países europeos, hasta la producción editorial de periódicos independientes y de oposición al gobierno. En todos ellos Posada y algunos contemporáneos fueron desarrollando un estilo que con destreza e imaginación reflejaba el ambiente popular e impulsaba la reflexión de las multitudes, con una constante búsqueda de contenidos a través de novedosas propuestas formales e invenciones técnicas para la realización de sus ilustraciones.

Al concluir la lucha armada, durante el gobierno de Álvaro Obregón, a partir de 1920 y bajo la dirección de José Vasconcelos, Secretario de Educación Pública, se inició un movimiento político y cultural que llevaría la historia de México y la ideología posrevolucionaria a las grandes masas de ciudadanos, campesinos y obreros a través de revistas, libros y el uso de la pintura mural de grandes dimensiones en edificios públicos.

Es en este ambiente que también promueve la cultura de México a través de los siglos, aquí destacan los dibujantes y pintores Francisco Díaz de León y Gabriel Fernández Ledesma que impulsan colecciones de libros de gran tiraje que pretenden llegar a todas las escuelas de educación básica del país.

Figura 4 Sobreproducción / litografía para filmina (1949). Leopoldo Méndez, CENIDIAP / INBA

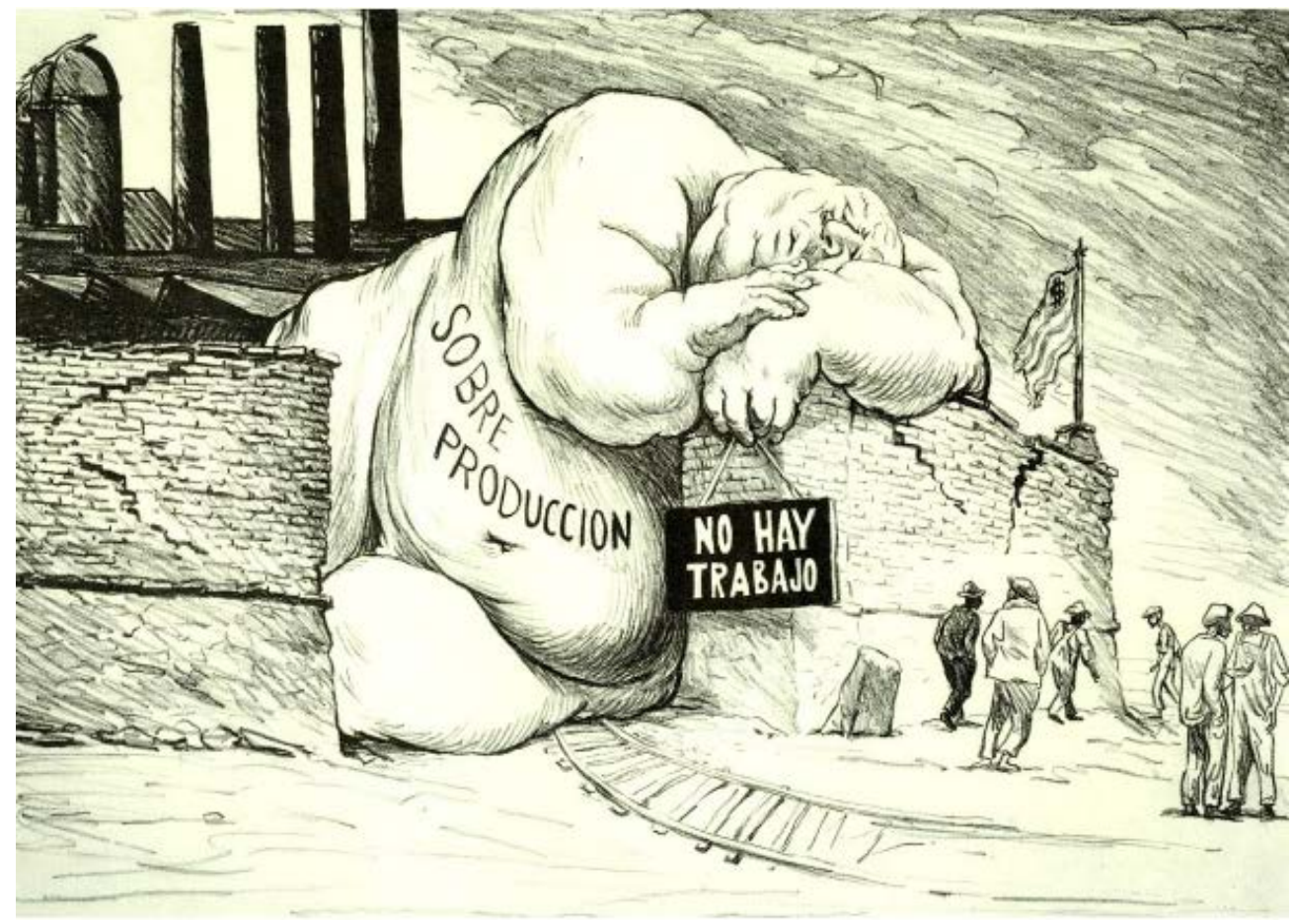




\section{El diseño llega desde el exilio}

Un capítulo sobresaliente que habla acerca de la solidaridad en la historia de México, fue el asilo que se otorgó entre 1938 y 1942 a miles de refugiados de la Guerra Civil Española. Cerca de veinte mil hombres, mujeres y niños a partir de entonces llegaron a México, que acabó siendo su nuevo hogar, y el efecto que tuvieron en el país tuvo una relevancia histórica tan importante, que todavía se mide su impacto. Del total de asilados, se estima que aproximadamente el 25\% estuvo formado por una élite de intelectuales, por lo que se puede decir que casi cinco mil notables llegaron para iniciar una nueva etapa de su vida colaborando en el desarrollo del país en un clima favorable, junto a militares, economistas, hombres de empresa y un número importante de obreros y campesinos de probada capacidad y vinculados al gobierno republicano, que se integraron de inmediato al sistema productivo de México.

La diversidad entre los refugiados notables fue muy amplia, y solo por mencionar a algunos, podemos destacar al cineasta Luis Buñuel, el músico Rodolfo Halffter, a la pintora surrealista Remedios Varo, los poetas León Felipe y Luis Cernuda, el científico Ignacio Bolívar y Urrutia, o los filósofos Adolfo Sánchez Vázquez y María Zambrano, que asumieron, como muchos más, la tarea de formar a varias generaciones de profesionales sembrando una obra trascendente en la cultura mexicana.

Como ya se ha dicho, México siempre ha sido un territorio con comunidades que han sobresalido por la calidad de sus representaciones visuales y gráficas, que emana desde las altas culturas de Mesoamérica, mismas que desarrollaron un complejo sistema de comunicación gráfica que se interrumpió con la conquista y el dominio del imperio español. No obstante, la riqueza pluricultural y el sincretismo emanado del encuentro entre las culturas indígenas y la combinación histórica de una península ibérica influida también por múltiples culturas, dio como resultado hasta antes del siglo XX, la integración de una sociedad mestiza rica en manifestaciones artísticas donde la gráfica mostrada a partir de la década de los años veinte, generó una potente revolución cultural que hizo de México un destino deseado por muchos artistas e intelectuales cuando se vieron en la necesidad de alejarse de una Europa que estaba por caer en un círculo de violencia e intolerancia.

Entre los miles de emigrados de la Guerra Civil, hubo también artistas plásticos que orientaron su futuro hacia las llamadas artes gráficas y es ahí donde encontramos a los artistas que vendrían a México a impulsar la disciplina del diseño gráfico con un objetivo primordial: orientar su trabajo hacia la promoción de la cultura. Me refiero a Josep Renau, Miguel Prieto y Vicente Rojo. 


\section{Josep Renau}

El valenciano Josep Renau, pintor, dibujante y amante de la fotografía, llega a México en 1939. Su actividad profesional antes y durante la Guerra Civil fue intensa y lo llevó a combinar su capacidad artística diseñando carteles, periódicos y revistas con diversas responsabilidades en el partido comunista y con el gobierno de La República en España. Al llegar es invitado por el pintor David Alfaro Siqueiros a colaborar en un mural y en los años cuarenta realiza un proyecto propio "España hacia América".

A pesar de su éxito inicial, vio que su futuro no estaba en la realización de obras extraordinarias, sino en un trabajo cotidiano que le diera de comer a su familia y le generara una posición de prestigio en su nueva patria. Organizó una verdadera empresa familiar que le permitió dentro de una sociedad en plena modernización, responder a una demanda casi frenética de todos aquellos que vieron que él era capaz de dar solución a sus necesidades, por su trabajo creativo, original y de gran calidad. Así es que funda una incipiente empresa de diseño, presentada con el singular nombre de "Estudio imagen, publicidad plástica”, desde donde realiza una de las colecciones mas importantes de carteles publicitarios para el cine mexicano en las décadas de 1940 y 1950 utilizando la técnica de fotomontaje, que siempre fue una de sus pasiones, y realizó una extensa recopilación de carteles y colaboraciones en revistas, prensa e incluso portadas para discos musicales de vinil, donde plasmaba con gran acierto la cultura y las tradiciones de México, igual que los temas de la modernidad internacional o cuando era posible, las piezas de crítica política de una ideología de izquierda que nunca abandonó.

Figura 5 Soledad. Cartel para película (1947). Josep Renau, Colección Instituto Mexicano de Cinematografía

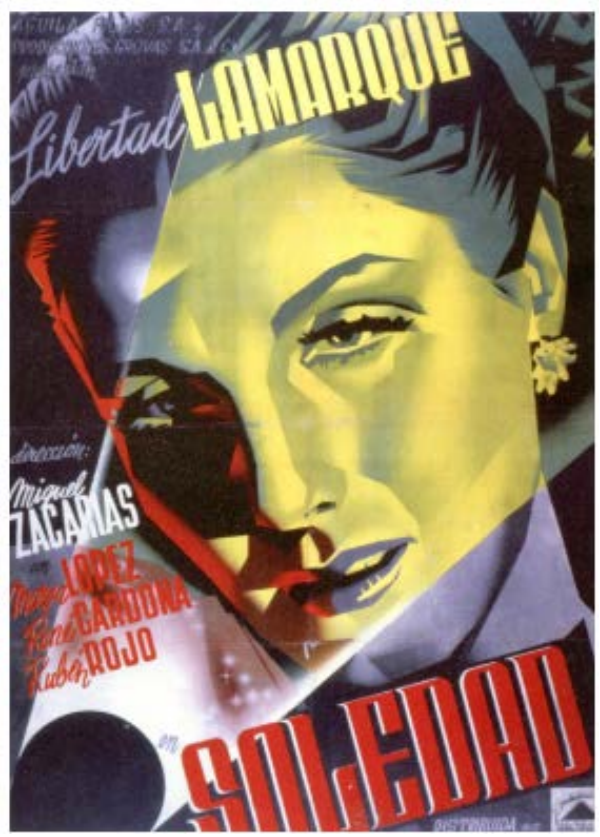




\section{Miguel Priet}

Tras la caída de la Republica Española, y después de vivir un tiempo con su familia en un campo de concentración en Francia, llegó a México en 1939 Miguel Prieto, que estudió en la Academia de San Fernando en Madrid para iniciar una formación diversa que lo llevó a ser tipógrafo, pintor, escenógrafo e incluso un entusiasta maestro del teatro guiñol.

$\mathrm{Al}$ arribar a México, casi de inmediato se incorporó a lo que sería su trabajo mas importante en su nueva patria, al formar parte del comité editorial de Romance, revista popular hispanoamericana, que fue una publicación memorable y un magnífico laboratorio para desplegar su talento en el diseño de tipografía y la composición editorial que después continuaría aplicando a varias revistas relacionadas con la creciente organización del exilio español. Eso le valió ser recomendado para colaborar con la Oficina de Ediciones del Instituto Nacional de Bellas Artes para rediseñar la revista México en el Arte, y después hacerlo también con el periódico Novedades, que publicaba el suplemento México en la Cultura, que durante varios años fue el mejor y mas comentado en el país por su rico contenido. Desgraciadamente, su trabajo se termina al morir prematuramente a los cuarenta y nueve años en 1956; sin embargo, sin proponérselo, sienta las bases del trabajo profesional del diseño gráfico dentro de las publicaciones sobre la cultura.

\section{Vicente Rojo}

Al final de la generación de exiliados españoles, encontramos a Vicente Rojo, nacido en Cataluña en 1932, que llega a México en 1949 para reunirse con su padre, que formó parte de los emigrados que arribaron diez años antes. En Barcelona había estudiado cerámica y escultura, y al llegar al país se inscribe en La Esmeralda, escuela de educación artística en la Ciudad de México, que abandona pronto buscando otra opción que lo condujera hacia una actividad profesional. A partir de 1950 trabaja con Miguel Prieto en las publicaciones del Instituto Nacional de Bellas Artes y el suplemento de México en la Cultura, donde aprende los secretos para lograr una gran calidad en esa disciplina en ciernes del diseño gráfico. Inicia así una larga vida profesional donde la creación para la cultura de México, sumada a la formación de jóvenes diseñadores, será su objetivo primordial. A partir de 1953 inicia una labor de promotor de la cultura dejando atrás la ilusión de retornar a la República perdida en la Guerra Civil. Conserva la solidaridad con la generación de exiliados españoles y la comparte con la generosidad del México culto que acepta su ofrecimiento para construir los proyectos que han formado un filón importante de la cultura mexicana.

Crea Artes de México, la publicación coleccionable de arte de mayor calidad hasta el momento; así mismo promovió la revista 
Vuelta, la de Artes Visuales del Museo de Arte Moderno, La Gaceta del Fondo de Cultura Económica, la Revista de Bellas Artes, la Revista de la Universidad de México, el diseño del periódico La Jornada. Además participó en el notable proyecto de la Imprenta Madero y la editorial ERA, en fraternal complicidad con la también exiliada Neus Espresate y su familia, dando cobijo a los grandes de la literatura Latinoamericana como Elena Poniatowska, Gabriel García Márquez, Carlos Fuentes y Octavio Paz entre otros notables autores.

Aunado a todo esto, Vicente Rojo ha sabido expresarse con éxito a través de la pintura, la escultura y el diseño de sus celebrados Libros de Arte, que produjo a la manera de Marcel Duchamp que se han convertido en piezas de gran valor para coleccionistas. No obstante, el mejor reconocimiento que se le ha dado en el medio del diseño, aparte de ser catalogado como el principal diseñador gráfico en el México de la segunda mitad del siglo XX, es la gratitud por haber asumido la responsabilidad de hacer escuela, de formar a los que hoy son los maestros de una disciplina en expansión y transformada por la tecnología, que sin embargo sigue reconociendo los principios y el sentido que Rojo aporta a la cultura del arte y el diseño. (véase Salinas Flores, 2018).

\section{La generación de los iniciados}

Vicente Rojo formó y guió en el oficio a un grupo de jóvenes comprometidos con el diseño gráfico, colaborando en sus proyectos y preparándose a su vez para ser la generación que inició la profesión con las grandes empresas y dio el ejemplo a las primeras generaciones de universitarios que estudiaron la disciplina en el país. Rafael López Castro, Luis Almeida, Germán Montalvo, Azul Morris, Efraín Herrera, Peggy Espinosa y Pablo Rulfo fueron algunos de esos diseñadores gráficos que sentaron las bases en los años setenta y ochenta del siglo $\mathrm{XX}$ para que la profesión se extendiera a todo el país.

Figura 6 izquierda: La sirena y otras figuraciones (1988). Serigrafía. Germán Montalvo, Colección OSF derecha: De sol a sol (1995), Serigrafía. Rafael López Castro, Colección OSF
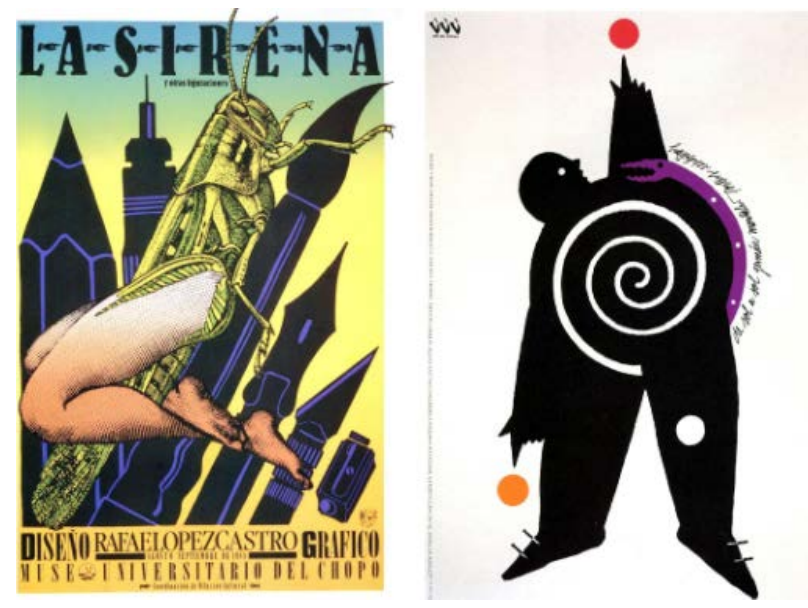
Figura 7 Firma de autor (1999), Crayón y lápiz. Gonzalo Tassier, Colección Trama Visual

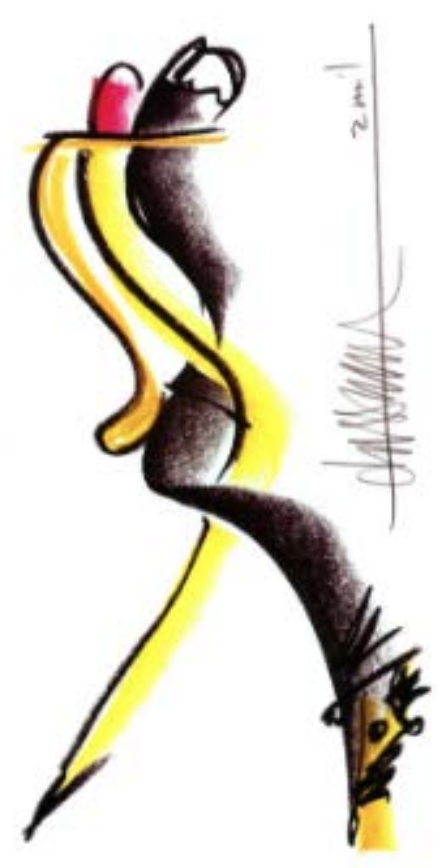

La primera Institución que abrió la carrera de Diseño Gráfico, fue la Universidad Iberoamericana, fundada por la orden de los jesuitas en 1968, aprovechando el trabajo fructífero que se venía desarrollando en el medio de la cultura y la gran difusión de la gráfica de los Juegos Olímpicos realizados en la ciudad de México en 1968. En los años setenta, la fundación del Centro de Diseño en el IMCE, Instituto Mexicano de Comercio Exterior impulsó la fundación de nuevas escuelas y la contratación de profesionales, frente a una oferta creciente de empresas locales y transnacionales que se instalaron en México en la búsqueda de nuevos mercados.

Durante los años noventa se presentó un fenómeno muy importante para el medio del diseño, cuando se generalizó el uso de la computadora y la digitalización en la concepción de los proyectos. El efecto de esta nueva tecnología tuvo consecuencias insospechadas y dio como resultado una correlación distinta con los clientes, con los procesos de producción y con los modos de comercialización.

El escenario del diseñador grafico empezó a transformarse rápidamente, porque además coincidió con un cambio profundo en los sistemas ideológicos. La recomposición geográfica de las naciones, así como la expansión considerable de los mercados globalizados promovieron marcas y productos que impusieron nuevos perfiles de vida a través de nuevas formas de comercialización en la mayoría de las ciudades urbanizadas, tendiendo así a la homogeneización y la estandarización de los objetos proyectados.

Ante esta situación, las disciplinas del diseño se han tenido que adaptar y transformar a la vez frente a los nuevos contextos, para encontrar también nuevos interlocutores. Se observó que el 
4 González de Cossío M. (2016). Diseño de información y vida cotidiana. $p$. 20; Cd. de México: Editorial Designio uso de la nueva tecnología colocó al diseñador en una situación ambivalente, pues en un principio ante la multiplicación de la oferta de diseños predeterminados en programas de software, el escaneo de documentos y la impresión por digitalización, ofrecida directamente al usuario, sin aparentemente requerir del diseñador, generó un clima de incertidumbre y la idea de no necesitar mas al especialista en el diseño gráfico. No obstante, en poco tiempo fue claro que la capacidad creativa y la posibilidad de generar nuevos productos gráficos para la sociedad, posicionaron de nuevo al diseñador no solo en el plano de lo estético, sino también en la generación de un proceso que los llevó al llamado diseño de información, a través de una comunicación mas clara y efectiva en los innumerables productos que requerían de un mayor entendimiento de los usuarios, que de esta manera se vieron transformados al interactuar mejor con el objeto diseñado. (González de Cossío, 2016, p. 20) .

\section{La profesión del siglo XXI}

Durante los años noventa y principios de este nuevo siglo, el crecimiento en el número de escuelas de Diseño Gráfico ha sido importante y la nomenclatura de los programas se ha venido modificando al buscar una relación mas efectiva con el medio social en que se desarrollan sus egresados. Hasta hace poco, al término Diseño le agregaron las capacidades que ubican al diseñador como un especialista en temas como la animación, el arte digital o la comunicación multimedia, a diferencia de la educación en el siglo XX que definía al diseñador gráfico en productos como diseño de carteles, etiquetas, imagen corporativa, editorial, empaque... en una lista tan larga como las cosas que les solicitaban con frecuencia en el mercado profesional.

Figura 8 Inicia Educación, Reporte Anual, (2015). Ideograma Consultores, Diseño Gráfico y Comunicación Visual, Archivo BID

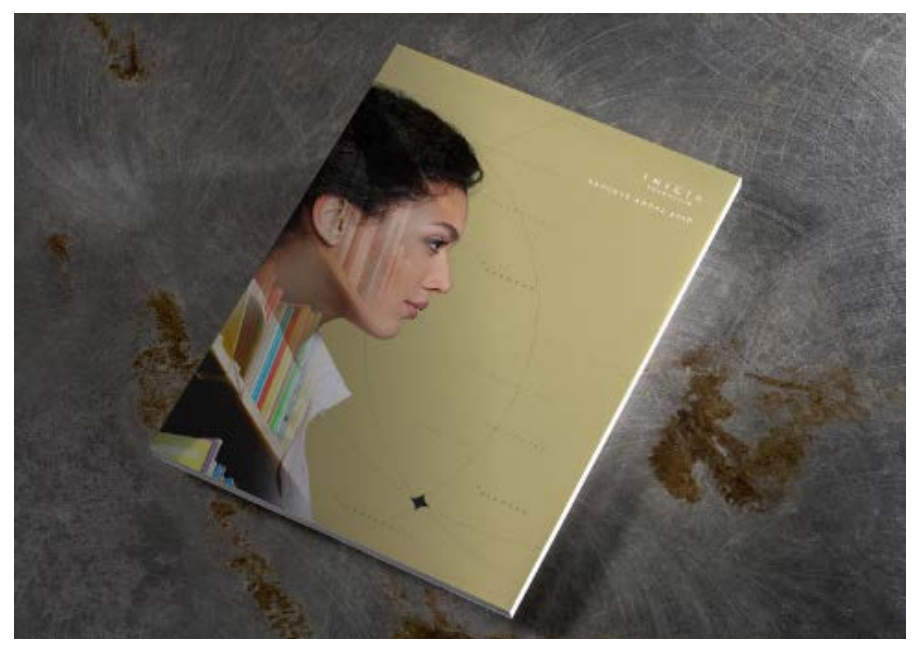


Esta generación de diseñadores ha dejado atrás el impacto inicial de la digitalización y el uso cada vez mas acelerado de la red mundial del internet, y acepta a las nuevas tecnologías como la herramienta de nuestro tiempo, encontrando todos los días nuevas posibilidades para su aplicación en el diseño. A diferencia de lo que se sostenía hacia el cambio de siglo, hoy se habla del diseño de interacción, de servicios, de experiencias, de sistemas complejos o de diseño participativo. $Y$ en cada uno de ellos encontramos diseñadores con un bagaje técnico y conceptual que les permite generar proyectos y ofrecer soluciones, en una posición creciente de interdisciplina e interacción que parte desde su acercamiento a pequeñas comunidades y termina en un nuevo perfil de diseñadores internacionalizados que se comunican y trabajan en conjunto vía internet desde diferentes países, pero con un proyecto en común. No obstante, hoy también se presenta un movimiento de críticos del "diseño perfecto y tecnologizado", que enfoca su práctica hacia un diseño "imperfecto" donde el proceso creativo y el lenguaje visual son usados para generar o imitar el trabajo manual, incluso usando los medios electrónicos mas sofisticados, para dar respuesta a un número también creciente de ciudadanos que viven la nostalgia por un mundo menos perfecto y estandarizado y un ambiente de vida mas emocional y tangible.

Es por eso que la gente busca un cartel producido con técnicas antiguas, numerado y firmado; o busca un libro impreso en papel, en contra de aquellos que anunciaban su desaparición frente al libro electrónico o busca escuchar la música en discos de acetato en antiguos reproductores de sonido, con la esperanza y el gusto de escuchar la acústica de la grabación original. Lo que es claro es que muchos diseñadores cada vez trabajan mas en interacción y experimentan con la interdisciplina y la transdisciplina construyendo productos de diseño que antes simplemente no existían. Los límites del diseño se han desdibujado y las capacidades profesionales del diseñador se presentan en constante transformación para responder a los retos que les impone la civilización del siglo XXI.

Figure 9 Escribe Escribano (2014) aplicación para iPad e Instalación Pública con 35 tipos móviles. Grupo Horma, Archivo BID
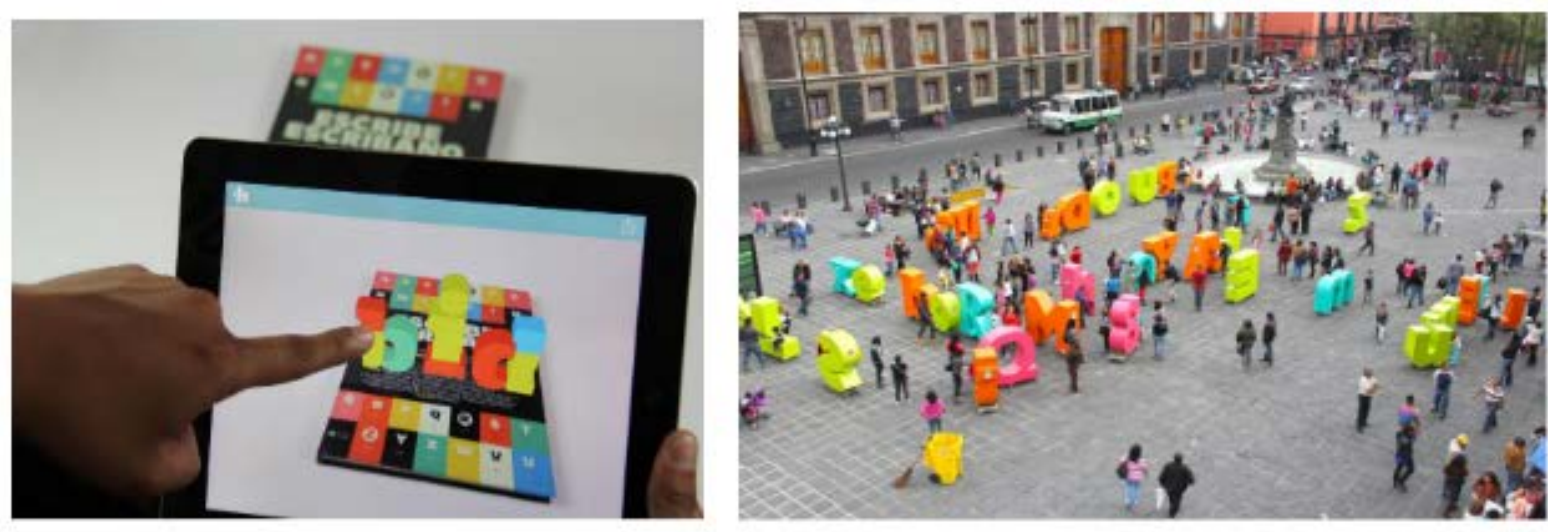
Figura 10 La Naríz (2014) Pieza de DCinema Expandido. Manuel Alcalá López y Carmen Ortega Casanovas. Proyecta / Plataforma Internacional de Diseño y Artes Digitales, Archivo BID

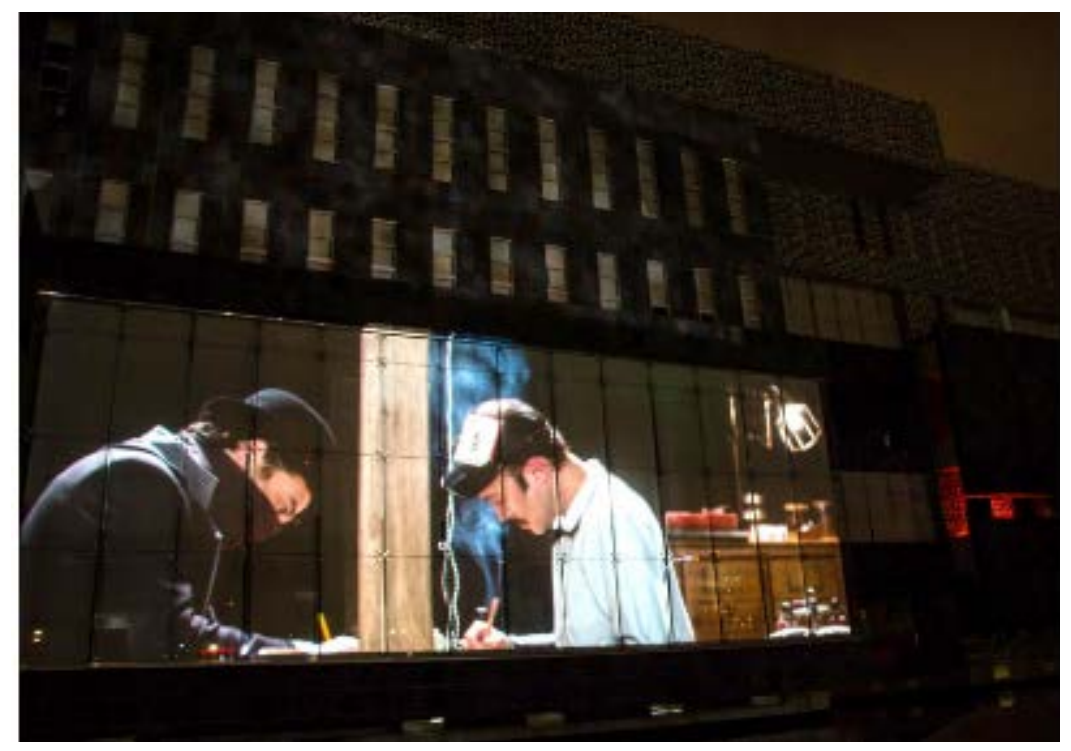

Al final, podemos observar que el diseño gráfico en México, igual que en un número creciente de países emergentes o desarrollados, se encuentra en una etapa de pluralidad ideológica y estilística, adoptando los perfiles profesionales que ha generado el nuevo contexto de nuestro entorno nacional, en una interdependencia cada vez mas compleja con la globalización y sus efectos.

El campo de trabajo se ha diversificado y los diseñadores transitan en diferentes ámbitos donde desarrollan sus ideas. Se enfrentan a un contexto que los ubica participando activamente en la mercadotecnia del planeta globalizado, en los nuevos medios de comunicación cada vez mas digitalizados y virtuales o impulsando los movimientos sociales que pugnan por un mundo mejor; todo ello en medio de una competencia profesional cada vez mayor, que tiene que responder a los cambios acelerados de los sistemas sociales y las nuevas tecnologías, sin saber claramente lo que puede pasar mañana.

\section{Referencias}

González de Cossío, M. (2016). Diseño de información y vida cotidiana. Ciudad de México: Editorial Designio.

Henestrosa, C (2005). Espinosa, rescate de una tipografía novohispana. Ciudad de México: Editorial Designio.

Medina, C. (1991). Diseño antes del Diseño. Diseño gráfico en México 1920-1960. Ciudad de México: Conaculta.

Musacchio, H (2007). El taller de la Gráfica Popular. Ciudad de México: Fondo de Cultura Económica.

Pérez Escamilla, R. (1994). Arriba el telón. Los litógrafos mexicanos, vanguardia artística y política del siglo XIX en Nación de Imágenes, La litografía 
mexicana del siglo XIX (p.19-41). Ciudad de México: Ediciones del Equilibrista y Turner Libros.

Salinas Flores, O. (2010). Tecnología y Diseño en el México Prehispánico. Ciudad de México: Editorial Designio.

Salinas Flores, Oscar. Por Franco. La diáspora del talento español a México; Diseño y Franquismo / $2^{\underline{o}}$ simposio de la Fundación Historia del Diseño. Febrero de 2018, Museu del Disseny, Barcelona

Téllez, E. y Hordoñez, P. (2000). Diseñadores Gráficos Mexicanos. Ciudad de México: Trama Visual

Troconi, G. (2010). Diseño Gráfico en México, 100 años, 1900-2000. Ciudad de México: Artes de México.

Vilchis Esquivel, L.C. ( 2010). Historia del Diseño Gráfico en México, 1900-2010. Ciudad de México: Conaculta.

\section{Autor:}

\section{Oscar Salinas Flores}

osalinas@unam.mx

Universidad Nacional Autónoma de México (UNAM)

Artículo presentado en 11/04/2019

Aprobado en 29/07/2019 